\title{
SISTEM PENDUKUNG KEPUTUSAN UNTUK PENGEMBANGAN AGROINDUSTRI PALA DI TALAUD
}

\author{
Rillya Arundaa ${ }^{* 1}$, Irman Hermadi*), dan Daniel RO Monintja ${ }^{* *}$ \\ *) Program Studi Ilmu Komputer, Sekolah Pascasarjana, Institut Pertanian Bogor \\ Jalan Meranti Kampus IPB Dramaga, Bogor 16680 \\ **) Departemen Pemanfaatan Sumberdaya Perikanan, Fakultas Perikanan dan Ilmu Kelautan, Institut Pertanian Bogor \\ Jl. Agathis Kampus IPB Darmaga, Bogor 16680
}

\begin{abstract}
Nutmeg (pala) is a plantation crop cultivated by the people of Talaud Islands, and it is one of the leading commodities in Talaud district. The main issue about the utilization of nutmeg is that there is no processing industry, so the utilization of nutmeg is not optimum. This condition could be the result of poor information and lack of decision making system that help stakeholders to decide on policy. The aim of this research is to design a decision support system (DSS) that can help business and government to make a decision related to planning and development of nutmeg agroindustry. The designed DSS consists of five models, namely, (1) location determination using Location Quotient (LQ) and Analytic Hierarchy Process (AHP) methods, (2) agroindustry products determination using AHP, (3) institutional determination using AHP, (4) market forecasting using linear regression, and (5) financial analysis using investment criterion. The development of DSS refers to research stages of System Development Life Cycle (SDLC) and uses an Object Oriented (OO) approach. This research has successfully designed a web-based decision support system to develop nutmeg agroindustry in Talaud. This system could help the users to process an alternative for nutmeg agroindustry development in Talaud because the assessment has been computerized and can be accessed anywhere through the internet.
\end{abstract}

Keywords: agroindustry, analytic hierarchy process, nutmeg, object-oriented, SDLC

\begin{abstract}
ABSTRAK
Tanaman pala merupakan salah satu komoditas perkebunan yang banyak diusahakan oleh masyarakat Talaud dan merupakan komoditas unggulan Kabupaten Kepulauan Talaud. Masalah utama yang terjadi adalah belum adanya industri pengolahan pala sehingga turunan buah pala seperti daging buah belum diolah dengan baik. Permasalahan tersebut disebabkan oleh kelangkaan informasi dan tidak adanya perangkat pengambil keputusan yang dapat membantu para stakeholder untuk menentukan kebijakan yang perlu dilaksanakan. Penelitian ini bertujuan membangun sebuah sistem penunjang keputusan (SPK) sehingga dapat membantu pelaku usaha dan pemerintah dalam mengambil keputusan yang berhubungan dengan perencanaan dan pengembangan agroindustri pala. SPK yang dibangun terdiri dari lima basis model yaitu (1) penentuan lokasi menggunakan metode Location Quotient (LQ) dan Analytic Hierarchy Process (AHP), (2) penentuan produk agroindustri menggunakan metode (AHP), (3) penentuan kelembagaan menggunakan metode AHP, (4) perkiraan pasar dengan metode regresi linier dan (5) analisis kelayakan finansial dengan menggunakan kriteria-kriteria investasi. Pengembangan SPK akan menggunakan pendekatan mengacu pada tahapan penelitian System Development Life Cycle (SDLC) dan menggunakan pendekatan pengembangan sistem Object Oriented (OO). Penelitian ini telah berhasil membangun sistem pendukung keputusan berbasis web untuk pengembangan agroindustri pala di Talaud. Sistem ini, memudahkan pengguna untuk proses penentuan alternatif pengembangan agroindustri pala di Talaud karena proses penilaian sudah dilakukan secara terkomputerisasi dan dapat diakses di berbagai tempat yang memiliki akses internet.
\end{abstract}

Kata kunci: agroindustri, analytic hierarchy process, object-oriented, pala, SDLC

\footnotetext{
${ }^{1}$ Alamat Korespondensi:

Email: rill.christy@gmail.com
} 


\section{PENDAHULUAN}

Tanaman pala merupakan tanaman buah berupa pohon tinggi asli Indonesia, karena tanaman ini berasal dari Banda dan Maluku. Sebagian besar pala dipasok dari wilayah timur Indonesia, terutama Maluku, Sangihe dan Talaud yang diekspor dalam bentuk rempah-rempah karena petani di sana cenderung untuk memanen pala yang sudah tua di pohon. Tanaman pala dikenal dengan tanaman rempah yang memiliki nilai ekonomis. Hasil tanaman pala yang biasa dimanfaatkan adalah buah pala (Nurdjannah, 2007).

Studi literatur yang dilakukan menunjukkan bahwa seluruh bagian buah pala dapat diolah menjadi berbagai produk turunan. Daging buah dapat diolah menjadi aneka produk makanan antara lain manisan pala, salad pala, sirup pala, jeli pala, selai pala dan sambal pala. Disamping produk-produk tersebut, daging buah pala dapat diolah menjadi sari buah pala, minuman instan pala, anggur pala, asam cuka, permen gelatin, dan permen pala (hard candy) (Nurdjannah, 2007). Biji pala terdiri atas tiga bagian, yaitu fuli, tempurung, dan daging biji. Fuli dan daging biji dapat diolah menjadi minyak atsiri, oleoresin dan mentega yang digunakan sebagai perisa pada industri makanan dan kosmetik. Sementara itu, ampasnya dapat dijadikan bungkil sebagai makanan ternak. Di samping itu, untuk tempurungnya dapat dimanfaatkan sebagai bahan baku dalam industri kimia.

Hasil survei BPS Talaud tahun 2014, pala merupakan salah satu komoditas unggulan Kabupaten Kepulauan Talaud dan merupakan tanaman yang banyak diusahakan oleh rakyat di Talaud dari tahun ke tahun. Produksi terbesar dari tanaman pala adalah dari usaha perkebunan rakyat dengan populasi tanaman diperkirakan mencapai 532.480 pohon, dimana $56 \%$ diantaranya merupakan tanaman produktif. Sebagaimana dipresentasikan dalam Tabel 1, tahun 2014 produksi pala rakyat sebanyak $4.445,65$ ton pada luas lahan 5.324,80 ha. Hasil survei memperlihatkan terjadinya peningkatan hasil produksi pala dari tahun ke tahun.

Ketersediaan hasil produksi, tidak diimbangi oleh kebijakan pemerintah pada kegiatan pengolahan pascapanen dan pemasaran. Pengusahaan hasil panen pala oleh petani umumnya dilakukan secara tradisional, yaitu dengan mengeringkan biji pala di bawah sinar matahari dan dijual dalam bentuk biji kering. Proses penjualan yang dilakukan belum mengikuti standar packaging yang baik. Penanganan yang tidak optimal tersebut mengakibatkan rendahnya produktivitas pala yang dihasilkan dan mengakibatkan rendahnya nilai jual seperti pada Tabel 1. Pengolahan buah pala tradisional yang hanya mengambil bagian biji pala ini, berdampak pada banyaknya limbah daging pala yang hanya dibuang oleh petani. Masalah tersebut disebabkan oleh belum adanya industri pengolahan pala sehingga turunan buah pala seperti daging buah belum diolah dan dimanfaatkan dengan baik. Masalah ini ditambah oleh ketidakpastian harga di tingkat pedagang dan pasar, yang disebabkan oleh monopoli pasar dari investor pala di pusat. Keadaan tersebut merugikan petani sehingga biaya usaha tani menjadi tinggi sedangkan harga jual kurang bersaing dan berakibat pada rendahnya nilai tambah yang diterima oleh petani pala. Selain itu, lemahnya penguasaan jaringan informasi tentang pasar sasaran menyebabkan kesulitan dalam mencari dan menemukan peluang pasar.

Ketersediaan sumber daya yang cukup (BPS Talaud, 2015) dan permintaan pasar yang tinggi (DITJENBUN, 2013) memberi indikasi bahwa tanaman pala memiliki potensi untuk menciptakan nilai tambah bagi setiap pelaku yang terlibat (Evalia, 2015). Potensi yang dimaksud yaitu dengan mengembangkan agroindustri pala. Pengembangan agroindustri pala ini diharapkan mampu direspons secara optimal oleh investor, pelaku usaha maupun oleh pemerintah sebagai pihak-pihak yang berkepentingan dalam agroindustri ini, sehingga dapat meningkatkan pendapatan dan menanggulangi permasalahan dalam pemberdayaan ekonomi masyarakat.

Pengembangan sektor agroindustri pala dipengaruhi oleh dua aspek penting, yaitu aspek penawaran dan permintaan. Aspek penawaran berkaitan dengan proses produksi yang dipengaruhi oleh faktor-faktor seperti bahan baku, jumlah dan kualitas tenaga kerja, teknologi pengolahan, dan penanganan akhir produk. Aspek permintaan dipengaruhi oleh faktorfaktor seperti harga produk, tingkat konsumsi, mutu produk, dan produk substitusi (Lolowang, 2012). Pengembangan agroindustri pala dipandang dapat memberikan alternatif strategi yang dapat dipakai untuk meningkatkan nilai tambah dan daya saing industri ini. Berdasarkan kenyataan tersebut, perlu dilakukan penelitian guna merumuskan langkah strategi pengembangan agroindustri berbasis pala guna mendapatkan nilai tambah yang dapat dinikmati langsung oleh petani. Strategi pengembangan yang 
dimaksud adalah merancang sebuah sistem pendukung keputusan (SPK). Keputusan yang benar dan tepat guna menjamin kemajuan dan keberlangsungan usaha agroindustri ini (Syam et al. 2006).

Banyaknya kriteria dan alternatif dalam pengambilan keputusan menyebabkan para pengambil keputusan mengalami kesulitan untuk memecahkan masalah (Eriyatno, 2012) sehingga dibutuhkanlah sebuah alat bantu analisis yang dapat membantu dalam proses pengambilan keputusan (Tafreshi et al. 2015). Salah satu alat analisis tersebut berupa multi-criteria decision making (MCDM) yang memungkinkan pengambilan keputusan untuk masalah yang bersifat kompleks (AbdullahdanAdawiyah, 2014; Stirn dan Grošelj, 2010). Salah satu dari metode MCDM yang banyak digunakan adalah analytic hierarchy process (AHP) (Agarwal et al. 2011; Aguarón et al. 2014). AHP memiliki banyak kelebihan dalam proses pengambilan keputusan karena cukup efektif dalam menyederhanakan dan mempercepat proses pengambilan keputusan dengan menguraikan keputusan kompleks menjadi bagianbagian keputusan yang lebih kecil (Dalalah et al. 2010; Kabir dan Hasin, 2011). Keunggulan lain AHP, yaitu dapat digambarkan secara grafis, sehingga mudah dipahami oleh semua pihak (pengguna) yang terlibat dalam proses pengambilan keputusan (Marimin et al. 2013).

Pengembangan industri berbasis pala melibatkan berbagai pihak yang terkait seperti investor, lembaga keuangan, pemerintah, konsumen, pelaku industri, penyedia bahan baku dan lembaga penelitian. Pihakpihak tersebut membutuhkan informasi yang beragam serta dapat disajikan dalam bentuk lengkap dan cepat. Penggunaan perangkat lunak (software) dapat memberikan kemudahan dalam pengambilan keputusan secara cepat, tepat, efektif dan efisien sehingga akan menghemat waktu dan biaya (Nyamsuren et al. 2015). Beberapa kelebihan dalam membangun aplikasi berbasiskan web (Kendall dan Kendall, 2011) adalah meningkatkan kesadaran akan tersedianya suatu layanan, produk, industri, orang atau kelompok, bisa diakses selama 24 jam oleh pengguna (user), menstandarkan desain antarmuka, menciptakan suatu sistem yang dapat diperluas secara global bukan hanya lokal sehingga mampu menjangkau orang-orang di tempat-tempat yang berjauhan tanpa mengkhawatirkan zona waktu lokasi mereka.

Tujuan penelitian ini adalah membangun aplikasi SPK yang akan membantu para pengambil keputusan mengenai perencanaan dan pengembangan agroindustri berbasis pala. Hasil akhir penelitian ini adalah sistem pendukung keputusan pengembangan agroindustri pala berbasis web yang dapat menentukan prioritas pengembangan agroindustri pala di Kabupaten Kepulauan Talaud, Sulawesi Utara.

\section{METODE PENELITIAN}

Penelitian telah dilakukan di Kabupaten Kepulauan Talaud Provinsi Sulawesi Utara, tepatnya di Kecamatan Kabaruan dan Kecamatan Damau karena merupakan sentra penghasil pala. Jenis dan sumber data yang digunakan data primer dan data sekunder. Data primer dikumpulkan melalui survei lapangan, wawancara, dan pengisian kuesioner oleh pakar. Pakar adalah mereka yang dianggap memiliki pengetahuan luas tentang pala dan agroindustri pala di Talaud. Data sekunder diperoleh dari Badan Pusat Statistik (BPS) dan Dinas Pertanian. Pihak-pihak yang dimintakan pendapat dan saran sebagai pakar adalah kepala dinas

Tabel 1. Hasil produksi, hasil pengolahan, dan harga tanaman pala di Talaud tahun 2009-2014

\begin{tabular}{ccccccc}
\hline \multirow{2}{*}{ Tahun } & \multirow{2}{*}{$\begin{array}{c}\text { Luas areal } \\
\text { tanaman pala (ha) }\end{array}$} & $\begin{array}{c}\text { Hasil produksi } \\
\text { tanaman pala } \\
\text { (ton) }\end{array}$ & $\begin{array}{c}\text { Biji kering } \\
\text { (ton) }\end{array}$ & $\begin{array}{c}\text { Fulli } \\
\text { (ton) }\end{array}$ & $\begin{array}{c}\text { Biji kering } \\
\text { (Rp/kg) }\end{array}$ & $\begin{array}{c}\text { Fulli } \\
\text { (Rp/kg) }\end{array}$ \\
\hline 2009 & $5.181,96$ & $3.553,48$ & 551 & 79 & 30.500 & 60.500 \\
2010 & $5.260,75$ & $3.553,48$ & 329 & 42 & 51.200 & 129.000 \\
2011 & $5.260,75$ & $3.525,85$ & 649 & 73 & 83.000 & 173.000 \\
2012 & $5.216,80$ & $3.526,70$ & 686 & 85 & 60.000 & 126.000 \\
2013 & $5.319,78$ & $4.177,72$ & 925 & 140 & 59.000 & 114.000 \\
2014 & $5.324,80$ & $4.445,65$ & 785 & 112 & 60.000 & 142.000 \\
\hline
\end{tabular}

Sumber: BPS Talaud, 2015. 
pertanian dan kehutanan Kabupaten Kepulauan Talaud, anggota Komisi B di dewan perwakilan rakyat daerah (DPRD) Kabupaten Kepulauan Talaud, kepala bidang perindustrian Dinas Perindustrian dan perdagangan Kabupaten Kepulauan Talaud, koordinator industri anggur pala "PORODISA" Kabupaten Kepulauan Talaud, dan petani pala.

Tahapan penelitian dalam penelitian ini seperti pada Gambar 1. Pada tahap perencanaan dilakukan analisis masalah, studi pustaka, identifikasi kebutuhan dan pengumpulan data. Pada kegiatan analisis masalah dilakukan identifikasi situasi, keadaan dan kondisi yang terjadi di tempat penelitian untuk memahami kebutuhan dan masalah yang terjadi serta menentukan solusinya. Langkah berikutnya dilakukan studi pustaka, pencarian dan pembelajaran literatur yang relevan. Selanjutnya, dilakukan identifikasi kebutuhan data primer dan sekunder, informasi mengenai jenis model keputusan, serta parameter model keputusan. Data dan informasi tersebut kemudian diverifikasi oleh pakar. Setelah itu, dilakukan pengumpulan data primer dan sekunder. Data primer dikumpulkan melalui survei lapangan, wawancara dan pengisian kuesioner oleh pakar, sedangkan data sekunder diperoleh dari Badan Pusat Statistik (BPS) dan Dinas Pertanian.

Pada tahap analisis dilakukan analisis model keputusan dan analisis sistem. Pada kegiatan analisis model keputusan, data primer dan sekunder dianalisis menggunakan beberapa metode seperti AHP, LQ, regresi linier dan kriteria-kriteria investasi, sesuai kebutuhan masing-masing model keputusan. Proses analisis ini menghasilkan bobot penilaian pada masingmasing model. Model keputusan dan bobot hasil penilaian pada tahap analisis selanjutnya digambarkan dalam bentuk diagram atau hierarki. Pada kegiatan analisis sistem dilakukan analisis kebutuhan sumber daya manusia (SDM), analisis kebutuhan pengguna, dan analisis kebutuhan sistem. Analisis kebutuhan sistem dimodelkan dengan diagram unified modeling language (UML).

Beberapa penelitian terdahulu yang meneliti tentang agroindustri pala diantaranya, Nugraha (2003) melakukan penelitian untuk studi pengembangan agroindustriminyak pala di Kabupaten Bogor. Penelitian ini menggunakan metode AHP untuk penentuan prioritas. Oryzanti (2003) melakukan penelitian dengan membuat perangkat lunak MYRISTICAN'S 1.01 untuk membantu pengambilan keputusan kelayakan investasi agroindustri minyak pala di Bogor. Penelitian ini menggunakan metode analisis kelayakan finansial umumnya seperti NPV, IRR, B/C Ratio, BEP, dan PBP. Model SPK yang dikembangkan terdiri atas tiga model: 1) model kelayakan usaha tani, 2) model kebutuhan bahan baku, dan 3) model kelayakan agroindustri. Haridian (2002) melakukan penelitian dengan membuat perangkat lunak PALADSS'02.1.01 untuk membantu pengambilan keputusan dalam perencanaan dan pengembangan agroindustri pala dengan studi kasus Kabupaten Bogor. Penelitian ini menggunakan Metode Perbandingan Eksponensial untuk menentukan prioritas alternatif dan analisis kelayakan finansial umumnya seperti NPV (net present value), $\mathrm{B} / \mathrm{C}$ ratio (benefit/cost ratio), Net B/C, IRR (internal rate of return), dan PBP (payback period).

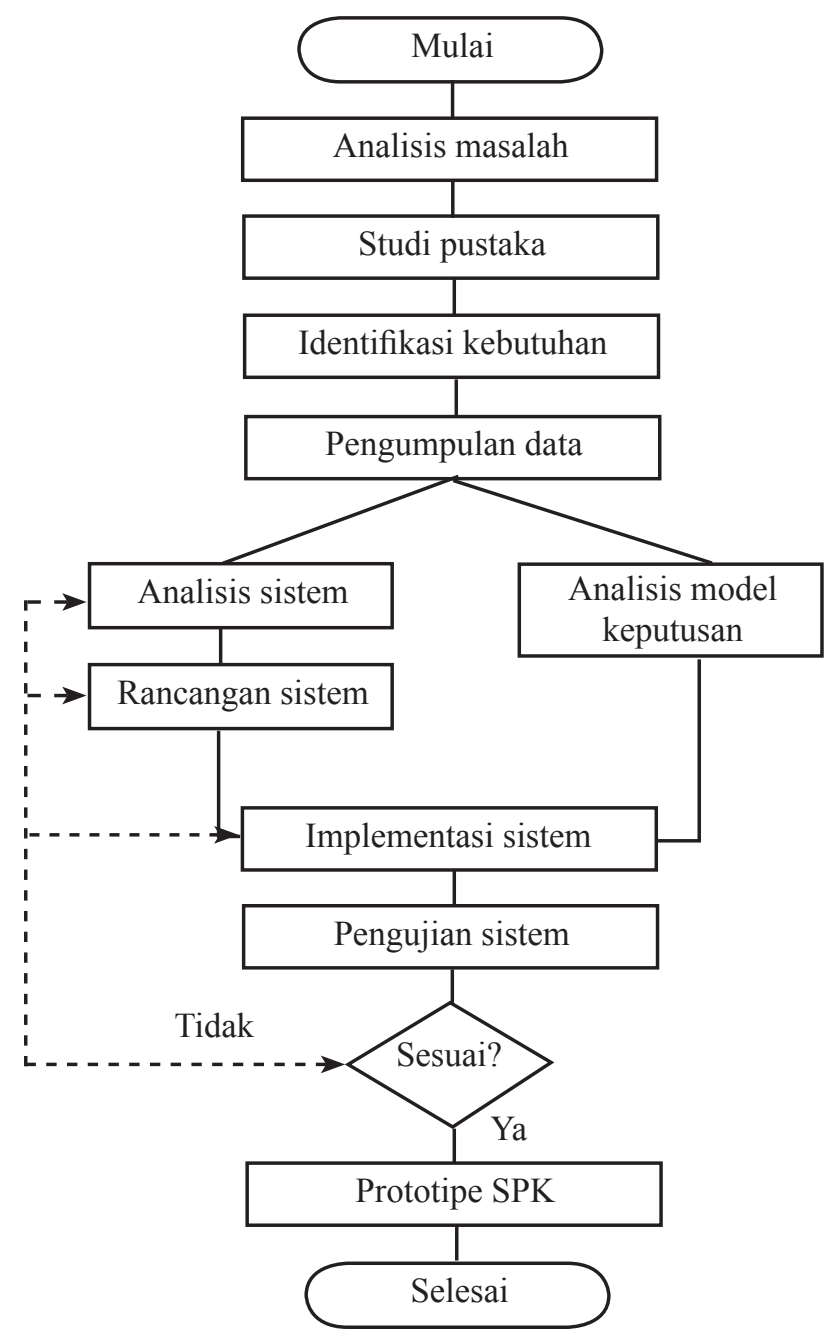

Gambar 1. Kerangka pemikiran penelitian 
Metode AHP digunakan untuk menganalisis penentuan prioritas produk agroindustri dan kelembagaan agroindustri. Metode LQ digunakan untuk mengindentifikasi alternatif lokasi pengembangan dan AHP untuk menentukan prioritas lokasi industri. Prakiraan pasar dianalisis menggunakan teknik prakiraan Regresi Linier sederhana. Kelayakan finansial agroindustri dianalisis menggunakan kriteria investasi meliputi: NPV, B/C ratio, Net B/C, IRR, dan PBP. Keluaran model didasarkan pada kondisi faktual selanjutnya disimulasi dengan menggunakan analisis sensitivitas yang bertujuan untuk mengetahui seberapa besar dampak atau risiko yang muncul jika satu atau beberapa faktor endogen mengalami perubahan. Faktor endogen yang disimulasikan tersebut adalah bahan baku dan harga jual produk di tingkat pabrik.

Setelah melakukan analisis sistem, tahap berikutnya dilakukan perancangan sistem. Pada tahap perancangan sistem dilakukan perancangan arsitektur sistem, basis data dan antarmuka. Aplikasi yang digunakan untuk membantu perancangan antarmuka adalah perangkat lunak Microsoft Visio 2010. Pada tahap implementasi dilakukan perancangan sistem menggunakan bahasa pemrograman berbasis web. Pada tahap ini juga dilakukan evaluasi prototipe sistem yang dibuat. Alat yang digunakan untuk mengimplementasikan prototipe tersebut adalah Xampp dan Google Chrome. Dalam tahap uji coba, dilakukan uji coba terhadap fungsionalitas sistem menggunakan metode black box testing.

\section{HASIL}

SPK yang dirancang terdiri dari sistem manajemen basis data, sistem manajemen basis model, sistem pengolahan terpusat dan sistem manajemen dialog. Pengembangan basis data membutuhkan beberapa data yang harus tersedia. Data primer yang dibutuhkan yaitu data kriteria dan alternatif penentuan prioritas produk agroindustri potensial, penentuan prioritas lokasi industri, dan penentuan kelembagaan agroindustri. Data sekunder yang dibutuhkan, yaitu data lokasi industri, permintaan pala dan produk hasil olahan pala, volume penjualan komoditas pala, luas areal tanaman pala, hasil produksi (panen) pala, produksi pala mentah, harga jual pala mentah, volume penjualan produk olahan pala, produksi produk olahan pala, harga jual produk olahan pala, dan struktur biaya investasi industri pengolahan minyak pala. Basis model dalam SPK pengembangan agroindustri pala terdiri dari lima model keputusan, yaitu model penentuan produk agroindustri, model penentuan lokasi industri, model kelembagaan agroindustri, prakiraan pasar komoditas dan agroindustri pala, dan analisis kelayakan finansial agroindustri.

\section{Model Penentuan Produk Agroindustri}

Struktur hierarki yang dibangun dalam model penentuan produk agroindustri terdiri atas goal, kriteria, aktor, tujuan dan alternatif produk agroindustri. Berdasarkan identifikasi diperoleh tujuh jenis produk agroindustri pala, yaitu industri minyak pala, industri anggur pala, industri manisan pala, industri sirup pala, industri jeli pala, industri selai pala, dan industri permen pala. Hasil identifikasi juga terdapat sembilan kriteria yang dipakai untuk menilai produk agroindustri yang paling sesuai untuk dikembangkan dalam pengembangan agroindustri pala di Talaud. Kriteria-kriteria tersebut yaitu permintaan, kontinuitas bahan baku, mutu bahan baku, ketersediaan fasilitas, sarana dan prasarana produksi, ketersediaan dana dan model, harga produk, keterampilan dan penguasaan teknologi, sumber daya manusia, dan pemasaran hasil produksi.

Pengembangan industri pengolahan pala mempertimbangkan faktor-faktor penting yang berpengaruh pada penentuan prioritas produk agroindustri pala. Hasil analisis menunjukkan bahwa faktor yang paling berpengaruh dalam pengembangan industri pengolahan pala adalah harga produk sebagai prioritas utama seperti dalam Tabel 2. Faktor lainnya yang juga berpengaruh adalah ketersediaan dana dan modal serta ketersediaan fasilitas, sarana, dan prasarana produksi.

Selain mempertimbangkan faktor-faktor yang berpengaruh, terdapat pula beberapa aktor yang memiliki peranan penting yang mempunyai bobot dan prioritas yang berbeda. Gambar 2 menunjukkan bahwa aktor yang menduduki prioritas pertama adalah Investor yang memiliki bobot tertinggi, selanjutnya di posisi kedua adalah Industri Hilir. Dengan konsistensi ratio untuk faktor permintaan $(0,03)$; kontinuitas bahan baku $(0,01)$; mutu bahan baku $(0,02)$; ketersediaan fasilitas, sarana dan prasarana produksi $(0,02)$; ketersediaan dana dan modal $(0,04)$; harga produk $(0,03)$; keterampilan dan penguasaan teknologi $(0,00)$; 
sumber daya manusia $(0,02)$; pemasaran hasil produksi $(0,04)$. Hal ini menunjukkan bahwa pasar agroindustri di Talaud masih didominasi dan sangat bergantung pada investor dari luar daerah seperti dari kota Manado. Salah satu parameter penting dalam keberhasilan dalam pengembangan agroindustri pala adalah dengan menetapkan tujuan yang jelas. Gambar 2 menunjukkan bahwa pemaksimalan keuntungan merupakan tujuan utama yang mempunyai bobot dan prioritas tertinggi. Dengan konsistensi ratio untuk aktor pemerintah $(0,00)$; investor $(0,04)$; industri hilir $(0,02)$; lembaga litbang $(0,01)$; lembaga keuangan $(0,01)$; penyedia bahan baku $(0,00)$.

Tabel 2. Hasil agregat faktor model penentuan produk agroindustri

\begin{tabular}{lcc}
\hline \multicolumn{1}{c}{ Faktor } & $\begin{array}{c}\text { Bobot } \\
\text { AHP }\end{array}$ & Prioritas \\
\hline Permintaan & 0,052 & 6 \\
Kontinuitas bahan baku & 0,044 & 8 \\
Mutu bahan baku & 0,057 & 5 \\
Ketersediaan fasilitas, sarana dan & 0,098 & 3 \\
prasarana produksi & & \\
Ketersediaan dana dan modal & 0,163 & 2 \\
Harga produk & 0,361 & 1 \\
Keterampilan dan penguasaan & 0,045 & 7 \\
teknologi & & \\
Sumber daya manusia & 0,098 & 3 \\
Pemasaran hasil produksi & 0,082 & 4 \\
\hline
\end{tabular}

Prioritas alternatif merupakan prioritas pengembangan agroindustri pala yang paling tepat. Dari hasil analisis dan perhitungan diperoleh bahwa industri minyak pala memiliki bobot tertinggi, yaitu 0,441. Hal ini berarti bahwa produk agroindustri yang paling tepat untuk pengembangan agroindustri pala adalah dengan mendirikan industri pengolahan minyak pala. Nilai konsistensi ratio yang ada menunjukkan bahwa penilaian yang dilakukan oleh pakar telah konsisten. Hasil selengkapnya dapat dilihat pada hirarki yang digambarkan pada Gambar 2.

\section{Model Penentuan Lokasi Industri}

Analisis LQ untuk menentukan daerah potensial lokasi industri dilakukan dengan membandingkan hasil produksi pala dan hasil produksi perkebunan secara keseluruhan. Berdasarkan analisis menggunakan metode LQ (Tabel 3) diperoleh bahwa dari 18 daerah yang mewakili kecamatan di Kabupaten Talaud, terdapat 7 (tujuh) daerah yang mewakili koefisien relatif yang lebih besar dari satu, yakni: 1) Kecamatan Kabaruan (1.301), 2) Kecamatan Damau (1.896), 3) Kecamatan Lirung (1.205), 4) Kecamatan Salibabu (1.699), 5) Kecamatan Kolongan (1.866), 6) Kecamatan Moronge (2.336), 7) Kecamatan Melonguane Timur (1.350). Hal tersebut menunjukkan bahwa daerah-daerah tersebut memiliki keunggulan relatif dibandingkan dengan daerah-daerah lain dalam hal ketersediaan bahan baku.

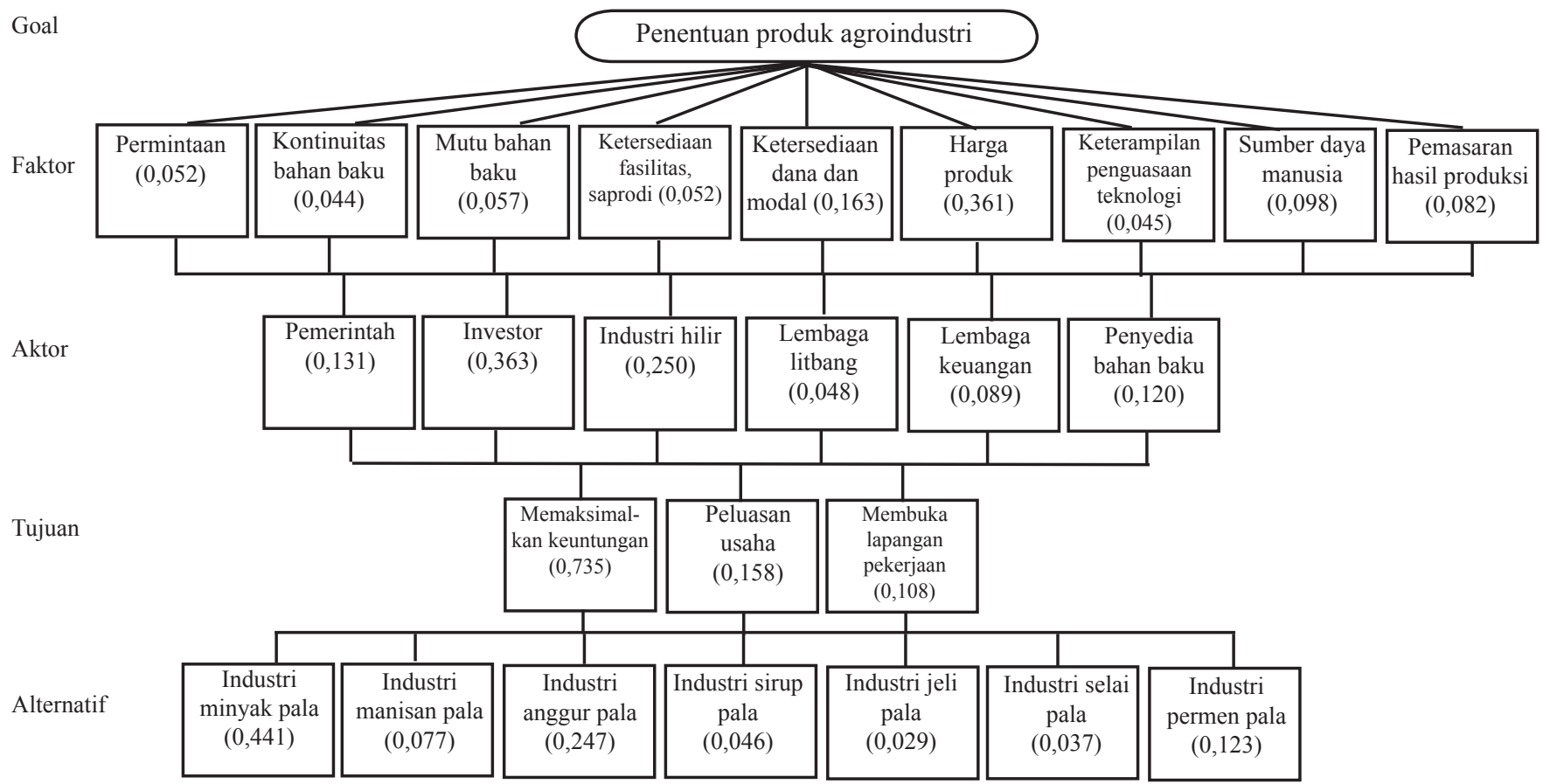

Gambar 2. Struktur hierarki dan bobot prioritas penentuan produk agroindustri pala 
Tabel 3. Koefisien LQ lokasi industri pala di Talaud

\begin{tabular}{lccc}
\hline Kecamatan & $\begin{array}{c}\text { Hasil } \\
\text { produksi } \\
\text { pala (ton) }\end{array}$ & $\begin{array}{c}\text { Hasil } \\
\text { produksi } \\
\text { perkebunan } \\
\text { (ton) }\end{array}$ & $\begin{array}{c}\text { Koefisien } \\
\text { LQ }\end{array}$ \\
\hline Kabaruan & 420,84 & 2060,88 & 1,301 \\
Damau & 568,86 & 1911,61 & 1,896 \\
Lirung & 121,95 & 644,86 & 1,205 \\
Salibabu & 452,84 & 1697,82 & 1,699 \\
Kolongan & 729,95 & 2492,94 & 1,866 \\
Moronge & 246,98 & 673,49 & 2,336 \\
Melonguane & 125,94 & 1529,54 & 0,525 \\
Melonguane & 321,98 & 1519,18 & 1,350 \\
Timur & & & \\
Beo & 129,93 & 1375,31 & 0,602 \\
Beo Utara & 115,90 & 1201,02 & 0,615 \\
Beo Selatan & 35,90 & 1135,23 & 0,201 \\
Rainis & 60,24 & 1521,34 & 0,252 \\
Tampan'amma & 40,91 & 1658,78 & 0,157 \\
Pulutan & 50,96 & 473,71 & 0,685 \\
Essang & 48,86 & 493,69 & 0,631 \\
Essang Selatan & 8,00 & 335,53 & 0,152 \\
Gemeh & 8,98 & 1010,66 & 0,057 \\
Nanusa & 8,52 & 548,63 & 0,099 \\
Jumlah & $\mathbf{3 . 4 9 7 , 5 4}$ & $\mathbf{2 2 . 2 8 4 , 2 2}$ & \\
\hline & & &
\end{tabular}

Hasil analisis lokasi dengan menggunakan LQ tersebut tidaklah cukup untuk dijadikan sebagai pertimbangan dalam penentuan lokasi industri karena kriteria yang dipakai sebagai pertimbangan dalam analisis hanya terbatas pada satu faktor yaitu jumlah hasil produksi. Walaupun demikian keluaran model yang diperoleh dapat memberikan informasi mengenai alternatif lokasi yang memiliki potensi untuk dikembangkan. Oleh karena itu, untuk menguatkan pengambilan keputusan lokasi industri maka analisis kemudian dikembangkan dengan menggunakan teknik AHP yang mempertimbangkan sejumlah kriteria penting yang diperoleh dari proses identifikasi.

Hasil identifikasi tersebut kemudian dilakukan pengembangan model lokasi prioritas dengan menggunakan teknik AHP di mana struktur model terdiri atas tiga tingkatan hierarki, yaitu tujuan, faktor, dan alternatif lokasi. Faktor-faktor yang digunakan dalam penentuan lokasi, yaitu konsentrasi geografis, ketersediaan lahan dan bahan baku, ketersediaan sarana transportasi dan komunikasi, ketersediaan listrik dan air, ketersediaan tenaga kerja dan potensi SDM, kondisi sosial ekonomi dan budaya kerja, ketersediaan infrastruktur fisik, ketersediaan lembaga pendukung, dukungan pemerintah daerah dan pusat, dan jangkauan pasar.

Hasil analisis menunjukkan bahwa faktor yang paling berpengaruh dalam penentuan lokasi industri adalah jangkauan pasar sebagai prioritas utama selanjutnya ketersediaan lahan dan bahan baku seperti dalam Tabel 4. Jangkauan pasar dilihat dari dua aspek, yaitu pasar lokal yang ada disekitar daerah industri (Kabupaten Talaud) dan pasar nonlokal (permintaan pasar diluar kabupaten Talaud). Kemudahan dalam hal jangkauan pasar akan memicu industri untuk terus berproduksi sehingga production cost akibat hasil olahan yang rusak maupun menumpuk bisa diminimalkan atau bahkan dieliminir. Dengan adanya jangkauan pasar yang dekat dan mudah, maka akan mengurangi kerugian industri.

Tabel 4. Hasil agregat faktor model penentuan lokasi agroindustri

\begin{tabular}{lcc}
\hline \multicolumn{1}{c}{ Faktor } & Bobot AHP & Prioritas \\
\hline $\begin{array}{l}\text { Konsentrasi geografis } \\
\text { Ketersediaan lahan dan bahan } \\
\text { baku }\end{array}$ & 0,035 & 9 \\
$\begin{array}{l}\text { Ketersediaan sarana transportasi } \\
\text { dan komunikasi }\end{array}$ & 0,044 & 7 \\
$\begin{array}{l}\text { Ketersediaan air dan listrik } \\
\text { Ketersediaan tenaga kerja dan } \\
\text { potensi SDM }\end{array}$ & 0,101 & 4 \\
$\begin{array}{l}\text { Kondisi sosial ekonomi dan } \\
\text { budaya kerja }\end{array}$ & 0,116 & 3 \\
$\begin{array}{l}\text { Ketersediaan infrastruktur fisik } \\
\text { Ketersediaan lembaga pendu- }\end{array}$ & 0,048 & 10 \\
$\begin{array}{l}\text { kung } \\
\begin{array}{l}\text { Dukungan pemerintah daerah } \\
\text { dan pusat }\end{array}\end{array}$ & 0,037 & 6 \\
Jangkauan pasar & 0,085 & 5 \\
\hline
\end{tabular}

Berdasarkan tujuan dan kriteria-kriteria tersebut, keluaran model menunjukkan bahwa lokasi industri di Talaud yang paling berpotensi adalah Lirung $(0,289)$. Dengan konsistensi ratio untuk faktor konsentrasi geografis $(0,03)$; ketersediaan lahan dan bahan baku $(0,03)$; ketersediaan sarana transportasi dan komunikasi $(0,03)$; ketersediaan listrik dan air $(0,01)$; ketersediaan tenaga kerja dan potensi $\operatorname{SDM}(0,02)$; kondisi sosial ekonomi dan budaya kerja $(0,02)$; ketersediaan infrastruktur fisik $(0,01)$; ketersediaan lembaga pendukung $(0,01)$; dukungan pemerintah daerah dan pusat $(0,01)$; jangkauan pasar $(0,03)$. Selengkapnya dapat dilihat pada Gambar 3. 
Penentuan lokasi agroindustri

\begin{tabular}{|c|c|c|c|c|c|c|c|c|c|c|c|c|c|c|c|c|}
\hline $\begin{array}{c}\text { Konsentrasi } \\
\text { geografis } \\
(0,035)\end{array}$ & $\begin{array}{c}\text { Ketersediaan } \\
\text { lahan dan } \\
\text { bahan baku } \\
(0,214)\end{array}$ & \multicolumn{2}{|c|}{\begin{tabular}{|c|} 
Ketersediaan \\
sarana transportasi \\
dan komunikasi \\
$(0,044)$
\end{tabular}} & \multicolumn{2}{|c|}{$\begin{array}{c}\text { Ketersediaan } \\
\text { listrik dan air } \\
\quad(0,101)\end{array}$} & \multicolumn{2}{|c|}{$\begin{array}{c}\text { Ketersediaan } \\
\text { tenaga kerja dan } \\
\text { potensi SDM } \\
(0,116) \\
\end{array}$} & \multicolumn{2}{|c|}{$\begin{array}{c}\text { Kondisi sosial } \\
\text { ekonomi dan } \\
\text { budaya kerja } \\
(0,025)\end{array}$} & \multicolumn{2}{|c|}{$\begin{array}{l}\text { Ketersediaan } \\
\text { infrastruktur } \\
\text { fisik }(0,048)\end{array}$} & \multicolumn{2}{|c|}{$\begin{array}{c}\text { ketersediaan } \\
\text { lembaga } \\
\text { pendukung } \\
(0,037)\end{array}$} & \multicolumn{2}{|c|}{$\begin{array}{c}\text { Dukungan } \\
\text { pemerintah } \\
\text { daerah dan } \\
\text { pusat }(0,085)\end{array}$} & $\begin{array}{c}\text { Jangkuan } \\
\text { pasar } \\
(0,295)\end{array}$ \\
\hline & \multicolumn{2}{|c|}{$\begin{array}{c}\text { Kabaruan } \\
(0,111)\end{array}$} & \multicolumn{2}{|c|}{$\begin{array}{l}\text { Damau } \\
(0,110)\end{array}$} & \multicolumn{2}{|c|}{$\begin{array}{l}\text { Lirung } \\
(0,289)\end{array}$} & \multicolumn{2}{|c|}{$\begin{array}{c}\text { Salibabu } \\
(0,101)\end{array}$} & \multicolumn{2}{|c|}{$\begin{array}{c}\text { Kolongan } \\
(0,086)\end{array}$} & \multicolumn{2}{|c|}{$\begin{array}{l}\text { Moronge } \\
(0,111)\end{array}$} & \multicolumn{2}{|c|}{$\begin{array}{l}\text { Moronge } \\
\text { Timur } \\
(0,191)\end{array}$} & & \\
\hline
\end{tabular}

Gambar 3. Struktur hierarki dan bobot prioritas penentuan lokasi industri

\section{Model Penentuan Kelembagaan Industri}

Model ini dikembangkan dengan metode AHP, struktur hierarki yang dibangun dalam model terdiri atas goal, faktor, aktor, tujuan dan alternatif kelembagaan agroindustri. Goal berupa tujuan pemilihan yaitu kelembagaan industri pengolahan pala yang efektif. Di level kedua terdapat faktor-faktor yang berpengaruh pada goal, yaitu ketersediaan informasi harga, akses permodalan, ketersediaan bahan baku dan pemasaran produk. Level ketiga adalah aktor yang berpengaruh diantaranya petani pala selaku penyedia bahan baku, investor, konsumen selaku pengguna produk olahan pala, eksportir, industri pengolahan, dan pemerintah. Level keempat adalah tujuan pendirian kelembagaan, yaitu memaksimalkan keuntungan, diversifikasi usaha, dan peningkatan mutu produk. Level kelima adalah alternatif kelembagaan yang nanti dibangun, yaitu menjalin kerja sama dengan industri hilir, industri hulu, dan menjalin kerja sama dengan industri hilir sampai hulu.

Input penilaian elemen dilakukan dengan menggunakan kuisioner hasil wawancara dengan pakar. Pembobotan oleh pakar dilakukan dengan memberikan nilai tiap elemen dalam tiap hierarki pada skala 1 sampai 9. Hasil analisis faktor terhadap goal menunjukkan bahwa faktor yang paling berpengaruh menentukan kelembagaan agroindustri pala adalah pemasaran produk sebagai prioritas utama seperti terlihat dalam Tabel 5.

Tabel 5. Hasil agregat faktor model penentuan kelembagaan agroindustri

\begin{tabular}{lcc}
\hline \multicolumn{1}{c}{ Faktor } & Bobot AHP & Prioritas \\
\hline Ketersediaan informasi harga & 0,073 & 4 \\
Akses permodalan & 0,198 & 3 \\
Ketersediaan bahan baku & 0,209 & 2 \\
Pemasaran produk & 0,520 & 1 \\
\hline
\end{tabular}

Selain menganalisis faktor-faktor yang berpengaruh, terdapat pula aktor-aktor berperan penting dalam penentuan kelembagaan agroindustri pala yang mempunyai bobot dan prioritas yang berbeda. Gambar 4 menunjukkan bahwa aktor yang menduduki prioritas pertama adalah Investor dengan bobot tertinggi selanjutnya Eksportir dengan bobot tertinggi kedua. Dengan konsistensi ratio untuk faktor ketersediaan informasi harga $(0,01)$; akses permodalan $(0,02)$; ketersediaan bahan baku $(0,02)$; pemasaran produk $(0,03)$.

Tujuan merupakan salah satu parameter keberhasilan dalam pengembangan kelembagaan agroindustri. Gambar 4 menunjukkan bahwa pemaksimalan keuntungan merupakan tujuan utama yang mempunyai bobot dan prioritas tertinggi. Dengan konsistensi ratio untuk aktor petani $(0,01)$; investor $(0,00)$; konsumen $(0,00)$; eksportir $(0,00)$; industri pengolahan $(0,00)$; pemerintah $(0,00)$. Dengan tujuan memaksimalkan keuntungan dapat mendorong tujuan yang lain yaitu diversifikasi usaha dan peningkatan mutu yang dihasilkan.

Prioritas alternatif merupakan prioritas pembentukan kelembagaan agroindustri pala yang paling tepat. Hasil alternatif ini dijadikan sebagai acuan untuk membentuk kemitraan dengan tujuan memaksimalkan keuntungan, diversifikasi usaha dan peningkatan mutu produk. Hasil analisis seperti terlihat pada Gambar 4 menunjukkan bahwa menjalin kerja sama dengan Industri Hulu - Hilir memiliki bobot tertinggi, yaitu 0,478. Dengan demikian kelembagaan yang dibentuk berupa kelembagaan mitra yang didalamnya terdapat kerja sama antara industri hulu sampai industri hilir. Diharapkan dengan adanya kemitraan ini setiap anggota dalam mitra tersebut dapat kepastian dalam memasarkan produk dengan harga yang lebih baik, melalui pembinaan setiap industri hilir selaku produsen 
pala dapat menghasilkan buah pala dengan mutu yang lebih baik, dengan bermitra kesempatan mendapat modal terbuka lebar baik dari perusahaan mitra ataupun dari lembaga keuangan. Adanya keterkaitan usaha ini dapat menciptakan kondisi saling membutuhkan yaitu kesempatan mendapat modal, baik dari perusahaan mitra ataupun dari lembaga keuangan. Dalam kondisi ini, diharapkan para pelaku kemitraan dapat saling membagi keunggulan di bidang teknologi, manajemen, permodalan ataupun akses pasar.

\section{Model Perkiraan Pasar}

Analisis komoditas pala dan agroindustri pala dihitung berdasarkan data historis yang terhitung selama enam tahun (2009-2014). Perhitungan untuk analisis tahun 2015 (ke-7), seperti pada Tabel 6.

\section{Model Analisis Kelayakan Finansial}

Analisis menggunakan kriteria investasi yang terdiri atas NPV, IRR, PBP, B/C Ratio, dan Net B/C. Keluaran model (Tabel 7) menunjukkan bahwa pada kondisi normal, investasi usaha agroindustri minyak pala layak untuk dijalankan. Hal ini terlihat dari nilai NPV yang bernilai positif dengan nilai sebesar Rp484.380.451. Nilai ini lebih besar dari nol, sehingga berdasarkan kriteria NPV usaha minyak pala layak untuk dilaksanakan. Perhitungan $\mathrm{B} / \mathrm{C}$ ratio dan $\mathrm{Net} \mathrm{B} / \mathrm{C}$ ratio menghasilkan nilai lebih besar dari 1, sehingga layak untuk dijalankan. Sementara itu, nilai IRR lebih besar dari tingkat diskonto yang digunakan, yaitu 18,5\% sehingga usaha minyak pala dengan kriteria IRR layak untuk dijalankan. Nilai Payback Period (PP) usaha ini selama 1,98 tahun. Nilai ini menunjukkan bahwa seluruh biaya investasi yang ditanamkan dalam usaha minyak pala akan dapat dikembalikan pada tahun ketiga, bulan kesembilan, hari ke 17 .

Goal

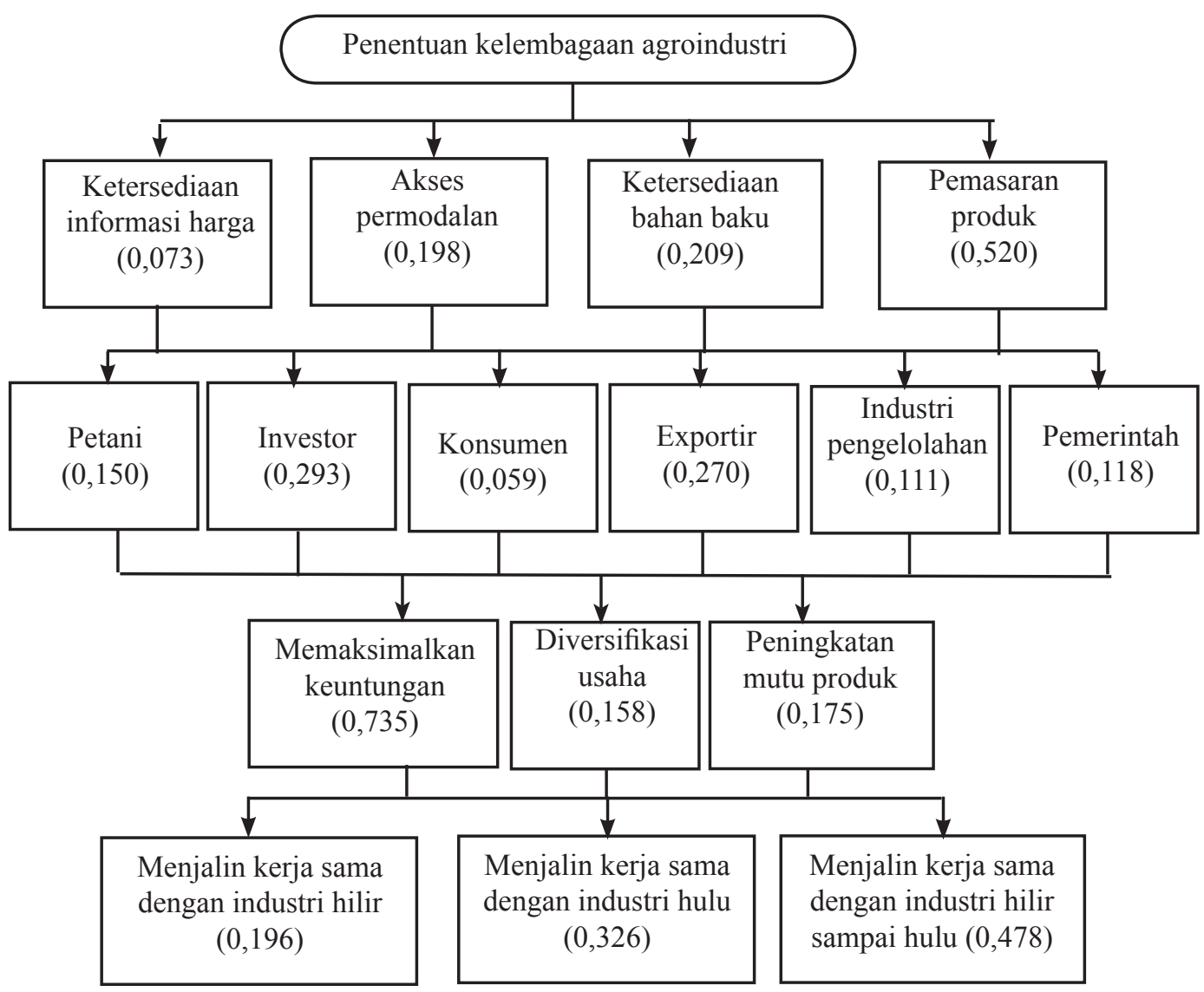

Aktor

Tujuan

Alternatif

Menjalin kerja sama $(0,196)$
Penentuan kelembagaan agroindustr

ahan baku

merintah

$0,118)$

Gambar 4. Struktur hierarki dan bobot prioritas kelembagaan agroindustri pala 
Tabel 6. Hasil prakiraan pasar komoditas dan agroindustri pala

\begin{tabular}{clccc}
\hline Tahun & Uraian & Hasil Prakiraan & R2 & Tingkat Akurasi \\
\hline 2015 & & Prakiraan pasar komoditas pala & $8 \%$ \\
& - Hasil produksi & 3767,20 ton & 0,08 & $62 \%$ \\
& - Volume penjualan & 953,67 ton & 0,62 & $22 \%$ \\
2015 & - Harga jual & Rp72.073 & 0,22 & $90 \%$ \\
& & Prakiraan pasar agroindustri anggur pala & $94 \%$ \\
& - Hasil produksi & 707 botol & 0,90 & $82 \%$ \\
\hline
\end{tabular}

Tabel 7. Koefisien indikator kelayakan investasi usaha agroindustri minyak pala pada kondisi normal

\begin{tabular}{lcc}
\hline \multicolumn{1}{c}{ Kriteria Finansial } & Nilai/Koefisien & Keterangan \\
\hline Net Present Value (NPV) & Rp 484.380.451 & Layak \\
Internal Rate of Return (IRR) & $36 \%$ & Layak \\
B/C Ratio & 1,33 & Layak \\
Net B/C & 1,15 & Layak \\
Payback Period (PP) & 1,98 tahun & Layak \\
\hline
\end{tabular}

Operasionalisasi perusahaan bisnis sering berhadapan dengan berubahnya faktor internal dan eksternal. Berdasarkan hal tersebut, dikembangkan analisis sensitivitas pada model kelayakan investasi dimana faktor-faktor yang diskenariokan yaitu perubahan harga jual produk dan harga bahan baku. Analisis sensitivitas dilakukan dengan tiga skenario, yaitu penurunan harga jual sebesar $10 \%$, peningkatan harga bahan baku sebesar $10 \%$, dan gabungan penurunan harga jual sebesar $10 \%$ dan peningkatan harga bahan baku sebesar 10\%. Keluaran model (Tabel 8) menunjukkan bahwa pada kondisi gabungan penurunan harga jual dan peningkatan harga bahan baku, usaha agroindustri minyak pala tidak menguntungkan atau tidak layak untuk dilaksanakan. Hal tersebut ditunjukkan oleh beberapa nilai koefisien yang tidak layak. Pada kondisi terjadi peningkatan harga bahan baku dan ketika terjadi penurunan harga jual, usaha agroindustri minyak pala masih memenuhi syarat kelayakan, walaupun nilai koefisien tersebut mengalami penurunan jika dibandingkan dengan investasi pada kondisi aktual. Hasil analisis sensitivitas menunjukkan bahwa setiap pelaku industri yang ingin berinvestasi pada usaha agroindustri minyak pala harus berhati-hati terhadap perubahan harga jual minyak pala.

\section{Analisis Sistem}

Sumber daya manusia yang dibutuhkan untuk pengembangan sistem ini yaitu pakar pertanian, ahli teknologi informasi, dan knowledge engineer. Pengguna utama dari SPK Agroindustri Pala ini, yaitu investor, pelaku industri, pemerintah, petani, lembaga penelitian, lembaga keuangan, konsumen, admin, knowledge engineer dan pakar. Sistem yang dibangun pada penelitian ini disebut Sistem Pendukung Keputusan Pengembangan Agroindustri Pala (De Pala). De Pala dibangun berbasis web sehingga dapat diakses kapan saja dan di mana saja selama terkoneksi dengan internet. Analisis kebutuhan sistem dimodelkan dalam bentuk diagram UML yang didalamnya terdapat class diagrams, use case, activity diagram, dan sequence diagrams. Aktor yang terlibat dalam sistem adalah petugas, pakar dan pengguna. Interaksi antara aktor dan fungsi-fungsi di dalam sistem digambarkan melalui diagram use case seperti ditunjukkan pada Gambar 5.

Petugas merupakan aktor yang bisa berinteraksi dengan semua fungsi, sedangkan pakar dan pengguna hanya bisa berinteraksi dengan beberapa fungsi tertentu. Pakar berinteraksi dengan use case memasukkan penilaian dan pengguna berinteraksi dengan use case melihat report, memasukkan komentar, dan memasukkan pesan. Use case yang terkait pengelolaan data selalu melakukan validasi apabila ada aktor yang mengaksesnya. Petugas memiliki hak akses untuk melakukan semua proses pengelolaan data. Hak akses tersebut meliputi proses pengelolaan data nilai, pengguna, model, petugas, pesan, komentar dan pakar. Pakar diberi hak akses untuk melakukan penilaian pada model penentuan produk agroindustri, lokasi agroindustri dan kelembagaan agroindustri. Pengguna merupakan istilah yang diberikan kepada pengunjung yang mengakses De Pala. Pengguna memiliki hak 
akses untuk melihat model SPK yang ada di De Pala, memasukkan komentar dan mengirim pesan. Semua aktivitas yang melibatkan petugas dan pakar harus melalui proses login, sedangkan semua aktivitas yang melibatkan pengguna tidak mengharuskan pengguna untuk login. Hal ini bertujuan memberikan kenyamanan serta kebebasan kepada pengguna untuk mengakses De Pala.

\section{Perancangan Sistem}

Arsitektur De Pala mengadaptasi model klien server Three-tier. Layer pertama berisi browser web yang berinteraksi dengan aktor (petugas, pakar, dan user) dan berfungsi mengambil dan menyajikan informasi pengembangan agroindustri pala kepada pengguna. Layer dua berisi web atau hypertext transfer protokol (HTTP) yang berfungsi menerjemahkan permintaan dan pengiriman data melalui PHP. Layer terakhir berisi data yang diminta klien.

Basis data De Pala terdiri atas 15 tabel. Pemodelan keputusan melibatkan tujuh tabel, yaitu tabel jenis model, model, faktor, aktor, tujuan, alternatif, dan nilai. Tabel jenis model digunakan untuk menyimpan data model. Tabel model digunakan untuk menyimpan data model keputusan pada De Pala. Kode model berelasi ke tabel faktor, aktor, tujuan, alternatif, regresi dan kelayakan finansial dengan relasi one to many. Tabel faktor digunakan untuk menyimpan parameterparameter faktor yang digunakan pada masingmasing model keputusan. Tabel nilai digunakan untuk menyimpan data penilaian pakar. Perancangan antarmuka sistem dirancang untuk memberikan gambaran, kemudahan, dan acuan pada tahap implementasi sistem. Perancangan sistem ini dibuat dengan menggunakan perangkat lunak Microsoft Visio 2010 .

\section{Implikasi Manajerial}

Dari hasil analisis dan perancangan, berikutnya dilakukan pengkodingan sistem berbasis web menggunakan bahasa pemrograman PHP dan basis data MySQL. Halaman utama De Pala dibuat sederhana, hanya berisi beberapa submenu dan deskripsi singkat tentang aplikasi De Pala. Banner bagian atas terdiri atas empat submenu, yaitu home, user page, about, dan login. Home akan membawa pengguna kembali ke halaman awal. User page disediakan bagi pengguna untuk melihat report tentang model-model keputusan yang ada di De Pala dan memasukkan komentar (Gambar 6). About merupakan deskripsi singkat tentang aplikasi De Pala. Login disediakan bagi petugas dan pakar untuk dapat mengakses halaman petugas maupun halaman pakar. Halaman admin menyediakan banyak fitur yang bisa diakses oleh petugas untuk melakukan manajemen sistem, berbeda dengan halaman pakar yang hanya terdiri dari submenu home dan kuesioner. Pengujian dilakukan menggunakan metode blackbox testing terhadap fungsi-fungsi yang telah dibangun pada De Pala. Sistem ini diuji oleh admin, pakar dan pengguna biasa/tamu.

Tabel 8. Analisis sensitivitas minyak pala terhadap penurunan harga jual dan peningkatan harga bahan baku

\begin{tabular}{lccc}
\hline \multirow{2}{*}{ Kriteria finansial } & \multicolumn{3}{c}{ Nilai/Koefisien } \\
\cline { 2 - 4 } & harga jual (-10\%) & bahan baku $(+10 \%)$ & harga jual (-10) \& bahan baku (+10\%) \\
\hline Net Present Value (NPV) & 102.339 .447 & 368.610 .450 & $(13.430 .554)$ \\
Internal Rate of Return (IRR) & $22 \%$ & $32 \%$ & $18 \%$ \\
B/C Ratio & 1,18 & 1,27 & 1,14 \\
Net B/C & 1,03 & 1,11 & 1,00 \\
Payback Period (PP) & 3,69 & 4,99 & 3,62 \\
\hline
\end{tabular}




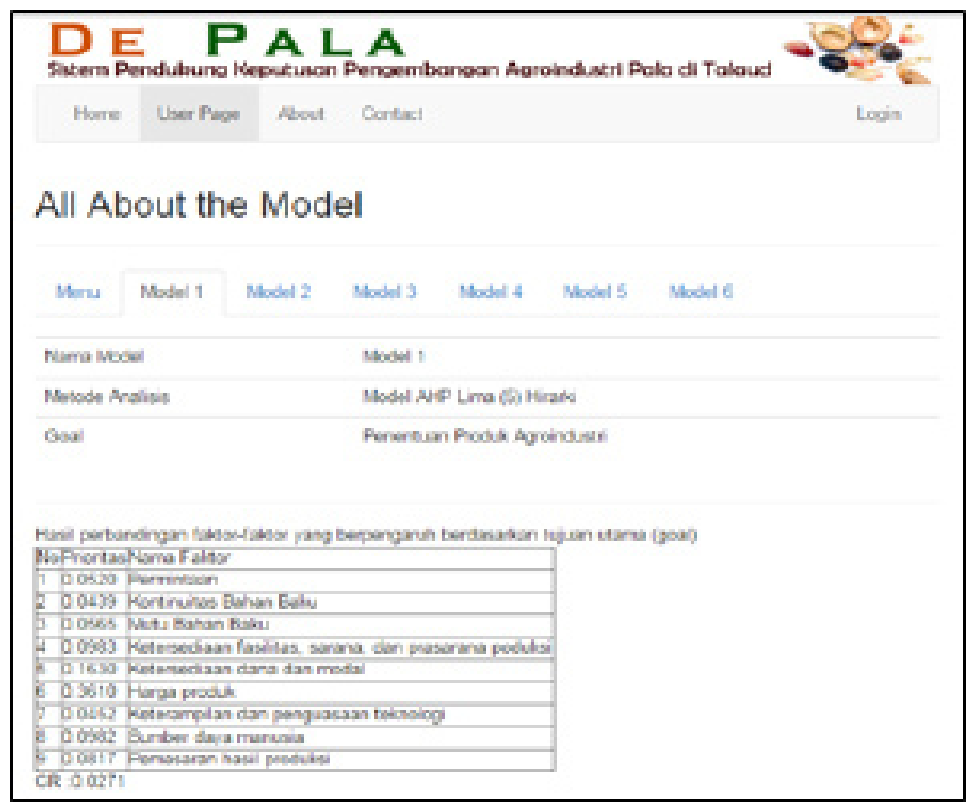

Gambar 5. Implementasi halaman user De Pala

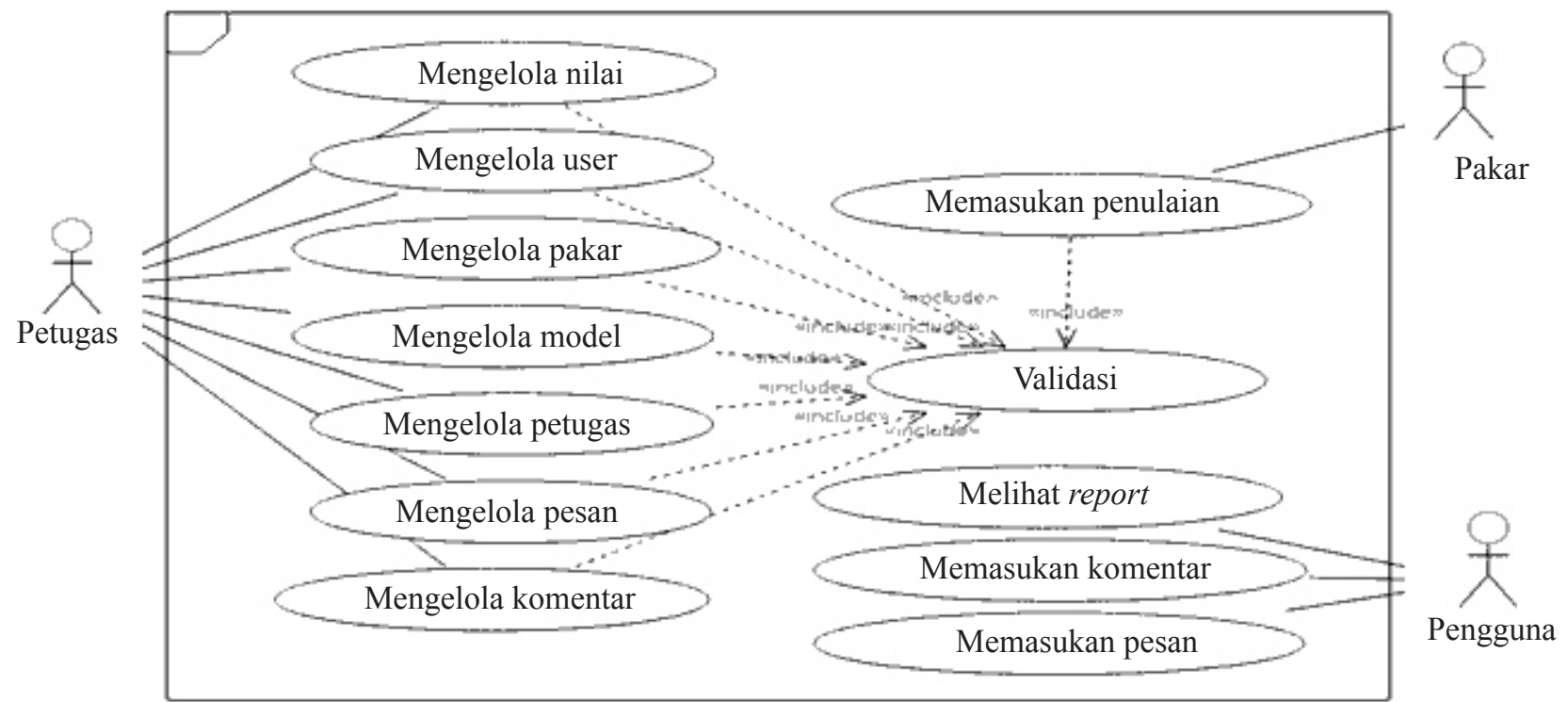

Gambar 6. Diagram use case De Pala

\section{KESIMPULAN DAN SARAN}

\section{Kesimpulan}

Penelitian ini telah berhasil membangun sistem pendukung keputusan berbasis web untuk pengembangan agroindustri pala di Talaud. Tahapan penelitian yang dilakukan terdiri dari analisis masalah, studipustaka, identifikasi kebutuhan, pengumpulan data, analisis model keputusan, analisis sistem, perancangan sistem, implementasi sistem, dan pengujian. Pada penelitian ini, metode AHP telah berhasil diterapkan untuk penentuan produk agroindustri dan kelembagaan agroindustri, gabungan metode LQ dan AHP diterapkan untuk penentuan lokasi industri, metode regresi linier diterapkan untuk prakiraan pasar komoditas pala dan agroindustri pala, serta kriteria-kriteria finansial diterapkan untuk analisis kelayakan investasi. Sistem pendukung keputusan pengembangan agroindustri pala di Talaud telah dikembangkan dan dibangun prototipenya. Prototipe dari sistem pendukung keputusan ini dinamakan De Pala. De Pala dibangun menggunakan bahasa pemrograman PHP, framework Yii, dan basis data MySQL. Dengan dibangunnya sistem ini, memudahkan pengguna untuk proses pengambilan keputusan dalam pengembangan agroindustri pala di Talaud karena proses penilaian sudah dilakukan secara 
terkomputerisasi dan dapat diakses di berbagai tempat yang memiliki akses internet. Sistem juga telah diuji dengan metode black box testing dan dapat berjalan dengan baik pada web browser Google Chrome, Mozilla Firefox, dan Internet Explore.

\section{Saran}

Sistem yang telah dibangun ini masih terkait komoditas perkebunan, yaitu pala. Bisa ditambahkan analisis model keputusan lainnya, seperti model rantai pasok, model strategi pengembangan dan model pemasaran. Pengembangan De Pala ini masih dalam bentuk prototipe sehingga perlu dilakukan implementasi ke internet

\section{DAFTAR PUSTAKA}

Abdullah L, Adawiyah CWR. 2014. Simple additive weighthing methods of multi criteria decision making and applications: a decade review. International Journal of Information Processing and Management 5(1):39-49.

Agarwal P, Sahai M, Mishra V, Bag M, Singh V. 2011. A review of multi-criteria decision making techniques for supplier evaluation and selection. International Journal of Industrial Engineering Computations 2:801-810. https:// doi.org/10.5267/j.ijiec.2011.06.004.

Aguarón J, Escobar MT, Moreno-Jiménez JM. 2014. The precise consistency consensus matrix in a local AHP-group decision making context. Annals of Operations Research 213(1):1-15

[BPS] Badan Pusat Statistik. 2015. Talaud dalam angka 2014. Talaud: BPS.

Dalalah D, Al-Oqla F, Hayajneh M. 2010. Application of the Analytic Hierarchy Process (AHP) in multicriteria analysis of the selection of cranes. Jordan Journal of Mechanical and Industrial Engineering 4(5):567-578.

[DITJENBUN] Direktorat Jenderal Perkebunan. 2013. Statistik Perkebunan Indonesia 2012-2014. Jakarta: DITJENBUN.

Eriyatno. 2012. Ilmu sistem: Meningkatkan Mutu dan Efektivitas Manajemen (jilid 1 edisi keempat). Surabaya: Guna Widya

Evalia NA. 2015. Strategi pengembangan agroindustri gula semut aren. Jurnal Manajemen dan Agribisnis 12(1):57-67.https://doi.org/10.17358/ JMA.12.1.57.
Haridian G. 2002. Sistem Penunjang Keputusan Perencanaan dan Pengembangan Agroindustri Pala [skripsi]. Bogor: Institut Pertanian Bogor.

Kabir G, Hasin MAA. 2011. Comparative analysis of AHP and Fuzzy AHP models for multicriteria inventory classification. International Journal of Fuzzy Logic Systems 1(1):1-16.

Kendall KE, Kendall JE. 2011. Systems Analysis And Design (8 thed). New Jersey: Pearson.

Lolowang TF. 2012. Rancang bangun model pengembangan klaster agroindustri aren di Sulawesi Utara [disertasi]. Bogor: Sekolah Program Pascasarjana, Institut Pertanian Bogor.

Marimin, Djatna T, Suharjito, Hidayat S, Utama DN, Astuti R, Martini S. 2013. Teknik Dan Analisis Pengambilan Keputusan Fuzzy dalam Manajemean Rantai Pasok. Bogor: IPB Press.

Nugraha A. 2003. Studi pengembangan agroindustri minyak pala (Nutmeg oil) di kabupaten Bogor [skripsi]. Bogor: Institut Pertanian Bogor.

Nurdjannah N. 2007. Teknologi Pengolahan Pala. Balai besar penelitian dan pengembangan pascapanen pertanian.http://pascapanen.litbang.deptan. go.id/assets/media/publikasi/juknis_pala.pdf. [30 Oktober 2014].

Nyamsuren P, Lee SH, Hwang HT, Kim TJ. 2015. A web-based collaborative framework for facilitating decision making on a 3D design developing process. Journal of Computational Design and Engineering 2(3):148-156. https:// doi.org/10.1016/j.jcde.2015.02.001.

Oryzanti P. 2003. Sistem Penunjang Keputusan kelayakan investasi agroindustri minyak pala (Myristica fragrans) di Bogor, Jawa Barat [skripsi]. Bogor: Institut Pertanian Bogor.

Stirn LZ, Grošelj P. 2010. Multiple criteria methods with focus on analytic hierarchy process and group decision making. Croatian Operational Research Review 1:2-11.

Syam H, Ma'arif MS, Eriyatno, Sailah I, Machfud, Didu MS. 2006. Rancang bangun model strategi sistem penunjang keputusan pengembangan agroindustri berbasis kakao melalui pola jejaring usaha. Jurnal Teknik Industri Pertanian 16(1):18-27.

Tafreshi PF, Aghdaie MH, Behzadian M, Abadi MG. 2015. Developing a group decision support system for advertising media evaluation: a case in the middle east. Group Decision and Negotiation 25(138):1-28. 